
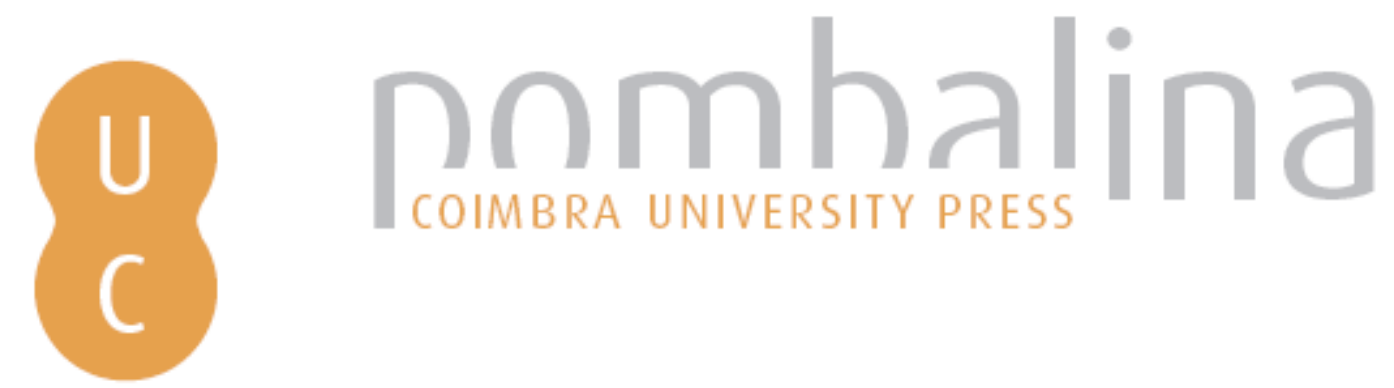

\title{
A relevância do De re ædificatoria na herança disciplinar da arquitetura clássica em Portugal: a influência da obra construída de Alberti
}

\author{
Autor(es): $\quad$ Pereira, António Nunes
}

Publicado por: Imprensa da Universidade de Coimbra

URL

persistente: URI:http://hdl.handle.net/10316.2/36686

DOI: $\quad$ DOI:http://dx.doi.org/10.14195/978-989-26-1015-3_24

Accessed : $\quad$ 26-Apr-2023 13:53:37

A navegação consulta e descarregamento dos títulos inseridos nas Bibliotecas Digitais UC Digitalis, UC Pombalina e UC Impactum, pressupõem a aceitação plena e sem reservas dos Termos e Condições de Uso destas Bibliotecas Digitais, disponíveis em https://digitalis.uc.pt/pt-pt/termos.

Conforme exposto nos referidos Termos e Condições de Uso, o descarregamento de títulos de acesso restrito requer uma licença válida de autorização devendo o utilizador aceder ao(s) documento(s) a partir de um endereço de IP da instituição detentora da supramencionada licença.

Ao utilizador é apenas permitido o descarregamento para uso pessoal, pelo que o emprego do(s) título(s) descarregado(s) para outro fim, designadamente comercial, carece de autorização do respetivo autor ou editor da obra.

Na medida em que todas as obras da UC Digitalis se encontram protegidas pelo Código do Direito de Autor e Direitos Conexos e demais legislação aplicável, toda a cópia, parcial ou total, deste documento, nos casos em que é legalmente admitida, deverá conter ou fazer-se acompanhar por este aviso.

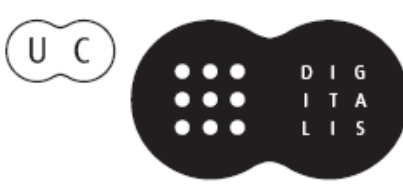


IMPRENSA DA

UNIVERSIDADE

DE COIMBRA

COIMBRA

UNIVERSITY

PRESS

\section{NA GÉNESE DAS RACIONALIDADES MODERNAS II}

Em torno de Alberti e do Humanismo

MÁRIO KRÜGER et alii

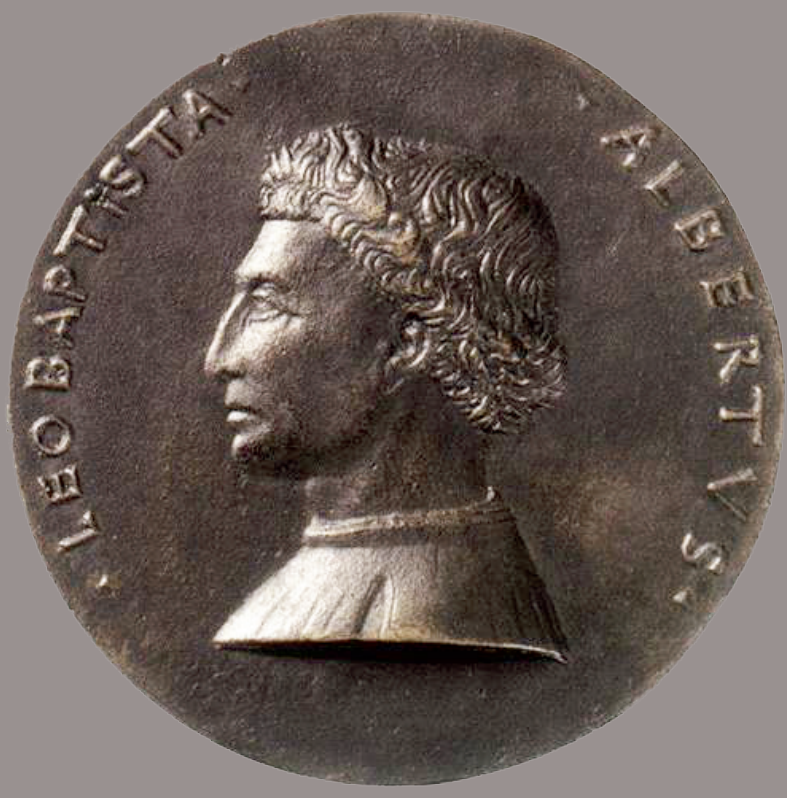


A RELEVÂNCIA DO DE RE AEDIFICATORIA NA HERANÇA DISCIPLINAR DA ARQUITETURA CLÁSSICA EM PORTUGAL:

\section{A INFLUENCIA DA OBRA CONSTRUída De ALBERTi}

António Nunes Pereira

\section{Resumo}

A influência da obra escrita e construída de Alberti na arquitetura portuguesa do Renascimento encontra-se pouco estudada. No entanto, ela pode ser constatada, tanto através de elementos inovadores na obra do arquiteto italiano que chegaram até ao nosso país, como através da constatação de proporções em edifícios portugueses, que Alberti tinha desenvolvido na sua obra escrita De re aedificatoria ou Da Arte Edificatória.

Obra escrita e construída de Alberti; Arquitetura Portuguesa do Renascimento; Proporção

\section{Résumé}

L'influence de l'oeuvre écrite et construite d'Alberti dans l'architecture portugaise de la Renaissance n'a pas fait l'objet de grandes études. Néanmoins on la retrouve autant dans des éléments innovants de l'oeuvre de l'architecte italien qui sont parvenus jusqu'à notre pays, comme dans les proportions des édifices portugais qu'Alberti avait développé dans son oeuvre écrite De re aedificatoria ou L'Art d'édifier. Oeuvre écrite et construite d'Alberti; Architecture Portugaise de la Renaissance; Proportions 


\section{Abstract}

The influence of the written and built work of Alberti in Portuguese Renaissance architecture is little studied. However, it can be verified both through innovative elements in the Italian architect work which arrive to our country, as by finding proportions in Portuguese buildings, which Alberti had developed in his writing De re aedificatoria.

Written and built work of Alberti; Portuguese Renaissance architecture; Proportions 
Avaliar a influência de Leon Battista Alberti na arquitetura portuguesa da Época Moderna seria antes de mais deslindar uma emaranhada teia de linhas de transmissão através da tratadística e da prática arquitetónica italiana - e, por extensão, da Europa ocidental - desde a obra escrita ou construída de Alberti até à arquitetura no Portugal do século XVI. Este tema está por investigar sistematicamente. Mas é possível constatar a presença de elementos na arquitetura portuguesa deste século e dos seguintes de origem na obra de Alberti - seja na construída, seja na escrita. Neste artigo pode-se apenas no atual estado da investigação reconhecer estes elementos mais óbvios e identificá-los em edifícios do nosso país. Não sendo possível olhar extensivamente toda a obra de Alberti enquanto possível modelo para o "modo ao romano" em Portugal, irei delimitar análise em dois polos: elementos tipologicamente inovadores da prática arquitetónica do mestre italiano com expressão na arquitetura portuguesa; e a teoria das proporções, no que respeita à obra escrita de Alberti. O objeto arquitetónico em Portugal e antigos territórios ultramarinos assume-se como documento histórico fundamental para esta análise, até pela precaridade de testemunhos escritos que nos fornecessem pistas sobre a influência de Alberti na prática arquitetónica portuguesa do século XVI.

São três estes elementos tipologicamente inovadores, que destaco da obra arquitetónica albertiana com relevância para o tema deste artigo:

A igreja de contrafortes interiores, resultante da tentativa de recriação de um templo etrusco e que Alberti concretizou na nave única e nas capelas laterais em Sant' Andrea em Mântua;

A introdução de aletas em fachadas-empena de igrejas para atenuar as diferenças de alturas inerentes à secção basilical, tal como em Santa Maria Novella de Florença;

A aplicação de articulação modular nas paredes exteriores de edifícios, trazendo para o exterior a modulação do edifício que estrutura o espaço interior (uma prática que já vem do período românico, mas que é rara no período clássico da Antiguidade e que Alberti concretiza com um rigor desconhecido no período medieval). 
Quanto à teoria das proporções, e à falta de mais estudos neste sentido referentes ao século XVI, ela terá que ser constatada, de acordo com o trabalho de investigação do autor, na arquitetura colonial portuguesa, como é o caso da igreja do Bom Jesus em Goa.

\section{A igreja de contrafortes interiores}

A igreja de contrafortes interiores foi uma das maiores inovações da arquitetura renascentista, que Alberti concretizou pela primeira vez a partir do início da década de 1470 para a igreja beneditina Sant' Andrea em Mântua. Na realidade, esta não é apenas uma inovação originária da prática projetual de Alberti, mas também da tentativa de Alberti reconstituir um templo etrusco, que o autor descreveu na obra teórica $D e$ re aedificatoria. 698

Esta inovação surge no fundo devido a um equívoco de Alberti, que testemunha o conhecimento deficitário, à época, da arquitetura da Antiguidade. Alberti julgou encontrar na Basílica de Maxêncio características e proporções semelhantes a um templo etrusco: 699 uma grande nave ladeada por três espaços abobadados de cada lado, funcionando as paredes que os separam também como contrafortes da abóbada da nave. Contudo, para a sua igreja Sant' Andrea, Alberti não se limitou a imitar e a repetir o tipo arquitetónico da Basílica de Maxêncio. $\mathrm{O}$ arquiteto italiano não utilizou uma abóbada de arestas, como a da nave da basílica romana, mas sim uma abóbada de berço. Mas a inovação mais significativa operada pelo arquiteto humanista foi a alternância entre capelas laterais de maior dimensão e planta retangular com capelas de menor

698 LEON BATTISTA ALBERTI, Da arte Edificatória, trad. de A. M. do Espírito Santo, introd., notas e revisão disciplinar de M. J. Krüger, Lisboa, Fundação Calouste Gulbenkian, 2001, pp. 439-442; ROBERT TAVERNOR, On Alberti and the Art of Building, New Haven and London, Yale University Press, 1998, p. 159. A justificação de Alberti fazer referência à cultura etrusca precisamente na edificação desta igreja de Sant' Andrea em Mântua, cidade que segundo Vergílio tinha sido conquistada pelos etruscos, estão expostas em ROBERT TAVERNOR, op. cit., p. 159.

699 ROBERT TAVERNOR, op. cit., p. 160. 
dimensão e de planta quadrada, inseridas entre os contrafortes da igreja, inscritos em planta, que suportam a abóbada da nave única. Os contrafortes surgem assim em pares, solução que contrasta com os contrafortes simples da Basílica de Maxêncio. O encontro destes contrafortes com as paredes laterais da nave é marcado por pilastras, igualmente duas a duas, ladeando os grandes arcos das capelas maiores e enquadrando as portas para as capelas laterais pequenas. Isto permitiu a Alberti configurar as paredes laterais da grande nave de Sant' Andrea com o tema de um arco de triunfo romano. Se por um lado Alberti repetiu deste modo no interior a articulação da fachada, a verdade é que o fez de uma maneira simplificada. Os tramos entre pilastras não mostram nichos sobre as portas para as capelas menores intermédias e, sobre aqueles, janelas, estas e aqueles de arco de volta inteira, mas sim painéis retangulares com pinturas e, por cima destes e logo abaixo da arquitrave, oculi. ${ }^{700}$

É nesta solução dos contrafortes interiores duplos, que permite não só a alternância entre capelas maiores e menores, assim como uma reminiscência do arco de triunfo romano no interior da igreja, que consiste a especificidade da solução inovadora de Alberti, uma vez que igrejas de nave única com capelas laterais existiram muitas antes de Sant' Andrea. ${ }^{701}$

Esta solução espacial para uma igreja de nave única serviu de modelo a inúmeras igrejas, sobretudo a partir do século XVI, quando as três ou mesmo cinco naves caíram em desuso. É também verdade que Sant' Andrea serviu de modelo não na forma em que Alberti a concebeu, ${ }^{702}$ mas juntamente com a ampliação de uma complexa cabeceira em cruz grega e cúpula sobre pendentes. Robert Tavernor atribui a Giulio Romano esta solução, que o arquiteto desenvolveu a partir de modelos da arquitetura religiosa de Roma, uma vez que as fundações da ampliação da

700 A hipótese de que o projeto inicial de Alberti previa para estas paredes laterais da nave de Sant' Andrea uma articulação em tudo correspondente à do arco de triunfo da fachada, enunciada em ROBERT TAVERNOR, op. cit., pp. 166 e 168, é muito interessante, mas não está comprovada.

701 Basta mencionar a igreja gótica do Convento de São Francisco de Évora (ca. 1480ca. 1503).

702 ROBERT TAVERNOR, op. cit., pp. 160-165. 
igreja foram lançadas em 1526, dois anos depois de Romano ter deixado aquela cidade para vir trabalhar nesta obra em Mântua. ${ }^{703}$ A grande aceitação de Sant' Andrea como modelo pode assim dever-se também a esta ampliação, cuja cúpula, para além da sua dimensão simbólica, confere monumentalidade ao edifício e sobretudo a possibilidade de iluminação superior no cruzeiro.

A popularidade desta solução arquitetónica deriva, contudo, menos diretamente de Sant' Andrea e mais de Il Gesù, a igreja do Colégio Romano dos Jesuítas iniciada por Giacomo Barozzi da Vignola em 1568, mas que reconhecidamente seguiu o tipo da igreja albertiana com as alterações na cabeceira de Giulio Romano. Em Il Gesù o transepto tornou-se inscrito na planta retangular da igreja, e sobre as capelas laterais foram introduzidos os coretti próprios da arquitetura religiosa dos Jesuítas. ${ }^{704}$ Também o tema do arco de triunfo romano, muito evidente em Sant' Andrea, foi atenuado em Il Gesù, pois nas paredes laterais da nave as superfícies entre as pilastras tornaram-se cegas - na realidade ao invés da citação de um arco de triunfo surgem aqui pilastras duplas que enquadram as aberturas das capelas laterais.

O grande dinamismo da Companhia de Jesus e as qualidades arquitetónicas do modelo de Sant' Andrea, filtradas por Il Gesù, levaram à sua difusão por quase todo o mundo. Em Portugal a receção deste modelo deu-se não num edifício jesuíta, mas num agostinho: a obra filipina de São Vicente de Fora (Fig. 1). São Vicente não apresenta os coretti das igrejas jesuítas e aproxima-se assim do modelo mais puro de Alberti. O corpo longitudinal de São Vicente repete o tipo albertiano de Sant'Andrea, mesmo que formalmente as divergências sejam evidentes, quer a nível das proporções, quer a nível da linguagem arquitetónica. A grande nave única, coberta com uma abóbada de berço, é ladeada por grandes capelas abertas para a nave através de arcos de volta inteira, que se alternam com espaços menores entre os contrafortes perpendiculares

703 Ibidem, pp. 165-167.

704 PIETRO PIRRI SI, Giovanni Tristano e i Primordi della Architettura Gesuitica, Roma, 1955, (Bibliotheca Instituti Historici SI, vol. VI), pp. 127-128, 131 e 176). 
ao eixo da abóbada (inexistentes em Il Gesù!). A filiação do tipo arquitetónico da igreja agostinha lisboeta em Sant' Andrea é evidente, apesar das divergências formais com a igreja beneditina de Mântua: as capelas menores da igreja agostinha não são quadrados em planta, mas retangulares e profundas, assumindo-se menos como capelas menores do que como espaços intermédios de passagem entre as capelas laterais de fato; também não enquadram na totalidade as três capelas de cada lado, totalizando quatro como na igreja albertiana, mas sendo pelo contrário enquadrados pelas capelas laterais, ficando-se por dois por cada lado da nave. Embora o tema do arco de triunfo romano esteja (potencialmente) presente nas paredes que delimitam lateralmente a nave de São Vicente, este encontra-se reduzido a um mínimo quase descaracterizado, que quase não chega para evocar a alternância entre tramos largos com grandes aberturas e tramos estreitos com aberturas pequenas e/ou nichos, que é o que caracteriza o tema do arco de triunfo romano. Na igreja lisboeta os panos menores apenas apresentam baixas portas, quase frestas, entaladas entre pilastras, longe da profusão de largas portas entre pedestais de pilastras, painéis e oculi com que Alberti enriqueceu Sant'Andrea. De resto, São Vicente segue o tipo de Sant'Andrea incluindo a ampliação de Giulio Romano, como Il Gesù de Roma já o havia feito e, seguindo mais de perto a igreja romana jesuíta que a de Mântua, apresenta o transepto inscrito. A existência de um retro-coro na igreja agostinha, contudo, veio a distorcer a clareza do tipo de planta grega, com que Giulio Romano configurou a cabeceira de Sant' Andrea - mas não sendo este um elemento de origem albertiana, não nos interessa debruçar mais sobre esta situação. Sobre a linguagem arquitetónica invulgar de São Vicente já muito foi escrito, podendo situar-se esta entre o classicismo depurado mas erudito de Juan de Herrera, uma simplificação à maneira da "arquitetura chã" provavelmente proveniente de Afonso Álvares e um maneirismo, onde a experimentação dos limites da linguagem clássica dá origem a soluções surpreendentes de mísulas triglifadas e de capitéis de ordem inventada. ${ }^{705}$

705 MIGUEL SOROMENHO, Classicismo, Italianismo e "Estilo Chão". O Ciclo Filipino, em "História da Arte Portuguesa", vol. II, Lisboa, Círculo de Leitores, 1995, pp. 377-403; 
A repercussão deste modelo em Portugal foi considerável, embora limitada sobretudo ao território continental, uma vez que nas colónias foi dada preferência a um outro modelo, mais antigo no país e a que se tem entendido como uma tradição jesuíta portuguesa. ${ }^{706}$ No entanto, a influência tipológica de Sant' Andrea no continente, foi bastante transformada através de São Vicente e, sobretudo e anteriormente, de Il Gesù. A alternância entre capelas laterais maiores e outras menores, ou mesmo simples espaços de transição, que na realidade caracteriza a criação tipológica albertiana, tende a simplificar-se em que os pares de contrafortes se fundem num único, desaparecendo os espaços menores, como já tinha acontecido em Il Gesù de Roma, mesmo que se mantenham as pilastras duplas como marcação deste contraforte nas paredes da nave. É o caso da primeira grande igreja que se seguirá a São Vicente, a jesuíta Onze Mil Virgens de Coimbra (iniciada em 1598; hoje Sé Nova) (Fig. 2). O que irá realmente caracterizar a receção do tipo de Sant' Andrea é sobretudo a nave única acompanhada de capelas laterais uniformes e cabeceira em planta de cruz latina com cúpula sobre o cruzeiro, que, como vimos, não é de origem albertiana. Isto verifica-se na acima mencionada igreja coimbrã, mas igualmente nas duas grandes igrejas do século XVIII, as Basílicas de Mafra (iniciada em 1717) e da Estrela (iniciada em 1779), em Lisboa. Deste modo, a influência da inovação albertiana acabou por se cingir a escassos exemplos tais como São Vicente ou a igreja do convento de São Domingos de Benfica, em Lisboa, em que a falta de pilastras na articulação das paredes da nave transforma surpreendentemente o tema de arco de triunfo albertiano numa quase serliana.

PaUlo VARela GOMES, Arquitetura, Religião e Política em Portugal no Século XVII. A Planta Centralizada, Porto, FUAP, 2001, pp. 158-159; ANTÓNIO NUNES PEREIRA, 1582: ano zero na arquitetura religiosa portuguesa?, em "Mosteiro de S. Vicente de Fora, Arte e História", coord. Sandra Costa Saldanha, Lisboa, Centro Cultural, Patriarcado de Lisboa, 2010, pp. 108-127, pp. 125-126.

706 MÁRIO CHICÓ, Algumas Observações acerca da Arquitetura da Companhia de Jesus no Distrito de Goa, "Garcia de Orta", número especial, 1956, pp. 257-271; ANTÓNIO NUNES PEREIRA, A arquitetura religiosa cristã de Velha Goa. Segunda metade do século XVI e primeiras décadas do século XVII, Lisboa, Fundação Oriente, 2005 (Orientália, n. ${ }^{\circ}$ 10), pp. 281-284 e 315-321. 


\section{A introdução de aletas em fachadas-empena de igrejas}

Leon Battista Alberti resolveu na fachada da igreja gótica de Santa Maria Novella (iniciada em 1458) de Florença um problema que tinha ficado em aberto desde o início do Renascimento, em particular nas igrejas longitudinais de Brunelleschi, San Lorenzo e Santo Spirito, ambas igualmente em Florença: como rematar de uma forma arquitetonicamente aceitável no contexto do Renascimento uma fachada-empena de corte basilical, em que os panos laterais - correspondentes às naves ou capelas laterais - eram mais baixos que o pano central - correspondente à nave principal ou única. Alberti resolveu este problema, atenuando o desnível entre cérceas através de elementos curvos em forma de $\mathrm{S}$ inclinado, as aletas, que faziam a transição gradual entre as cérceas superior e inferiores da fachada. Esta solução pensada para uma igreja de secção basilical de três naves viria a ter grande aceitação, até por se mostrar igualmente adequada ao novo tipo de igreja de nave única ladeada por capelas mais baixas. Mais uma vez foi Il Gesù de Roma o veículo de disseminação desta solução. Embora o autor do projeto geral da igreja, Giacomo Barozzi da Vignola, tivesse previsto para a fachada desta igreja jesuíta uma solução muito simplificada - apenas elementos parietais de curva simples - foi Giacomo della Porta que, na fachada efetivamente construída de sua autoria, retomou e aperfeiçoou a solução albertiana, criando volutas de encaracolamento contrário nos extremos dos Ss e dando-lhe assim um caráter pré-barroco.

Em Portugal encontramos tanto esta solução de aletas, como também a solução em elementos de curva simples que, não sendo estritamente albertiana, é contudo dela derivada.

O caso mais interessante é (mais uma vez) o das Onze Mil Virgens de Coimbra (Fig. 3), onde a solução de aletas à maneira de Il Gesù foi conjugada com a solução de fachada de duas torres, ainda que recuadas, que se impunha desde São Vicente de Fora. ${ }^{707}$ Algo semelhante acontece

707 ANTÓNIO NUNES PEREIRA, "1582: ano zero na arquitetura religiosa portuguesa?", em Mosteiro de S. Vicente de Fora, Arte e História, coord. Sandra Costa Saldanha, Lisboa, Centro Cultural, Patriarcado de Lisboa, 2010, pp. 108-127, pp. 119-120. 
com a igreja, também jesuíta, de São Lourenço no Porto (Fig. 4), onde desta vez as aletas estão inseridas na construção das próprias torres. A preferência no nosso país por fachadas de duas torres impedirá uma maior difusão da solução albertiana em aletas para fachadas de igrejas longitudinais de secção basilical.

Esta solução de aletas encontrou eco também na longínqua Goa, embora perdendo a função original de interligação de cérceas de diferentes alturas. Aqui, as aletas em conjugação com um pano de parede central com frontão, constituem o remate na fachada de uma empena de telhado de duas águas, em lugar de um frontão clássico. Refiro-me às igrejas do Bom Jesus (começada em 1594, sagrada em 1605) (Fig. 5) e de Nossa Senhora da Graça (1597- terminada após 1608) (Fig. 6).

A solução com elementos curvilíneos simples à maneira de Vignola em Il Gesù teria igualmente expressão em Portugal. A mais antiga é provavelmente a da igreja do Espírito Santo de Évora (construída de 1567 a 1574) (Fig. 7), cujo projeto de $1566^{708}$ é anterior em dois anos ao início da igreja do colégio de Roma. ${ }^{709}$ Mas também as igrejas lisboetas de São Francisco da Cidade e do Colégio de Santo Antão, ambas destruídas no terramoto de 1755, tinham os elementos curvilíneos simplificados à maneira de Vignola, segundo as reconstituições do Museu da Cidade lisboeta. ${ }^{710}$ Enquanto em São Francisco os elementos estavam soltos, em Santo Antão encontravam-se inseridos nas torres da fachada. Em Goa tanto a desaparecida igreja de São Paulo (1560) do colégio jesuíta, como a sé (iniciada após 1564-1652) apresentam estes elementos. Contudo, enquanto na igreja jesuíta eles serviam de fato como interligação na fachada entre naves de diferentes alturas, no caso da sé trata-se de um remate na fachada de uma

708 FAUSTO SANCHES MARTINS, A arquitetura dos primeiros colégios jesuítas de Portugal: 1542-1759: cronologia, artistas, espaços. Dissertação de doutoramento, Universidade do Porto, 1994, p. 210.

709 Sabe-se que nesta altura havia um grande fluxo de informação dentro da Companhia de Jesus, o que torna plausível que o projeto de Vignola para Il Gesù já fosse conhecido em Portugal antes do início da sua construção; PIETRO PIRRI SI, Giovanni Tristano e $i$ Primordi della Architettura Gesuitica, Roma, 1955, (Bibliotheca Instituti Historici SI, vol. VI), pp. 89-93.

710 www.museudacidade.pt/Lisboa/3D-lisboa1755/Paginas/default.aspx, última consulta em 07.08.2014. 
empena de telhado de duas águas, em lugar de um frontão clássico, de uma forma similar às já referidas Bom Jesus e Nossa Senhora da Graça.

\section{A aplicação de articulação modular nas paredes exteriores de edifícios}

Este é um ponto de maior dificuldade em se traçar uma linha de evolução, sobretudo que reconduza a Alberti. É no entanto reconhecida a importância da inovação de Alberti no Palácio Rucellai em Florença. ${ }^{711}$ Pela primeira vez no ainda jovem Renascimento um edifício apresentava a sua fachada com uma articulação de pilastras e entablamentos, constituindo uma grelha que a dividia em módulos horizontais e pisos. Esta situação não é completamente inédita na Antiguidade, embora se conheçam apenas exemplos de edifícios públicos com articulação exterior e sempre baseada na combinação coluna (ou coluna embebida) e entablamento: coliseus e anfiteatros são os exemplos mais óbvios, mas há também a insólita Biblioteca de Adriano em Atenas com as suas colunas soltas face a uma parede cega, tal como outros exemplos de arquitetura romana, de que destaco a Biblioteca de Celsius, em Éfeso na Turquia, ou a Porta do Mercado de Mileto, originalmente também na Turquia, mas reconstituída no Museu Pergamon de Berlim, após escavações em 1903-1905. Mas esta solução de Alberti para uma palácio urbano privado era inédita no Renascimento e acabou por ter uma grande repercussão na arquitetura, quer profana, quer religiosa. A disseminação do tipo de fachada articulada do Palácio Rucellai ficou também certamente a dever-se aos tratados de Cesario Cesariano ${ }^{712}$ e sobretudo de Sebastiano Serlio, ${ }^{713}$ cujas ilustrações de arquitetura palaciana frequentemente recorrem a esta solução albertiana.

711 ROBERT TAVERNOR, On Alberti and the Art of Building, New Haven and London, Yale University Press, 1998, pp. 81-89; LUDWIG H. HEYDENREICH, Architecture in Italy 1400-1500, revised by Paul Davies, New Haven and London, Yale University Press, 1996, pp. 39-40.

712 CESARE CESARIANO, Vitruvius de Architectura, fac-símile da $1^{\text {a }}$ edição italiana (Como, 1521), ed. Carol Herselle Krinsky, Munique, 1969, libro IV, p. LIIII.

713 SEBASTIANO SERLIO, Tutte l'Opere d'Architettura et Prospetiva, di Sebastiano Serlio Bolognese, fac-símile (Veneza, 1619), Nova Iorque, 1964, libro VII, pp. 195 e 215. 
Em Portugal o exemplo mais proeminente na arquitetura civil é o Palácio Ducal de Vila Viçosa, cuja fachada foi realizada pelo duque D. Teodósio em 1535, sendo acrescentado um piso adicional em 1601. ${ }^{714}$ Outras obras seguir-se-iam usando este modelo de articulação, de que destaco o Torreão do Paço da Ribeira de Filipe Terzi, cuja configuração influenciaria a fachada do palácio para o Terreiro do Paço, tudo isto desaparecido no terramoto de 1755.

A influência deste tipo de articulação albertiana na arquitetura religiosa é ainda mais complexa de se averiguar. Certo é que antes da fachada do Palácio de Rucellai a arquitetura religiosa não revelava nas fachadas e paredes exteriores o sistema modular de abóbadas em tramos no interior, que era a regra sobretudo em igrejas longitudinais desde o período do Românico (existem algumas igrejas com articulação exterior, como é o caso da Catedral de Pisa; mas esta articulação não corresponde à organização espacial interior; é sobretudo um tratamento plástico de fachada; as igrejas de Brunelleschi e do próprio Alberti mostram que uma articulação exterior em harmonia com toda a articulação espacial do edifício não era corrente). As igrejas mais antigas que mostram esta articulação exterior em módulos de pilastras e entablamentos são Santa Maria delle Carceri, no Prato (Giuliano da Sangallo, iniciada em 1485) e Igreja de Santa Maria della Consolazione em Todi (começada em 1508 por Cola da Caprarola), ambas de planta centrada. Mas mais do que para igrejas de planta centrada, a articulação modular albertiana adequava-se a igrejas longitudinais, cuja métrica interior de divisão em tramos poderia ser transposta para o exterior. Em Portugal é mais uma vez São Vicente de Fora que apresenta não só na fachada, mas também nas paredes laterais uma articulação que no exterior revela a estrutura e métrica espacial interior (Fig. 8). Esta situação verificar-se-á igualmente noutros edifícios de grande dimensão como as sés de Portalegre e Leiria. Contudo, mais do que no continente, foi em Goa que esta articulação em grelha que Alberti ensaiou no Palácio Rucellai teve grande aceitação, tornando-se uma das

714 RAFAEL MOREIRA, "Uma 'Cidade Ideal em Mármore', em Monumentos, 6, 1997, pp. $48-53$, p. 51. 
características principais da arquitetura religiosa goesa, que a distinguem da congénere portuguesa. ${ }^{715}$ Este tipo de articulação em grelha pode ter sido realizada pela primeira vez na igreja do Convento de São Domingos (1550), mas rapidamente se tornou na regra de configuração de fachadas e paredes exteriores na totalidade dos volumes das igrejas. Se em São Paulo e na sé de Goa a articulação em módulos de dois pisos ainda se relaciona em grande parte com a configuração espacial interior (Fig. 9), no caso das igrejas de Nossa Senhora da Graça e sobretudo do Bom Jesus a divisão em módulos horizontais, mas em particular nos três pisos, tornou-se um fim em si mesma, autónoma em relação ao espaço interior (Fig. 10). Esta divisão modular em pisos tornou inclusivamente a ordem colossal praticamente inexistente na arquitetura goesa de origem portuguesa. ${ }^{716}$

\section{Teoria das Proporções}

Quanto à influência da obra escrita de Alberti, em particular no que respeita à teoria das proporções, na arquitetura portuguesa "ao romano", este é um campo ainda menos estudado. Se esta influência de Alberti se faz sentir diretamente a partir da obra do humanista, ou indiretamente através de outros media, é incerto. Certo é que a prática arquitetónica portuguesa revela conhecimento desta doutrina projetual, embora numa extensão ainda desconhecida. Como exemplo apresenta-se aqui o resultado de um estudo realizado na igreja do Bom Jesus de Goa, no âmbito de um projeto coordenado pelo autor deste artigo e financiado pela Fundação para a Ciência e Tecnologia. ${ }^{717}$ Para esta análise utilizou-se uma planta de reconstituição

715 ANTÓNIO NUNES PEREIRA, A arquitetura religiosa cristã de Velha Goa. Segunda metade do século XVI e primeiras décadas do século XVII, Lisboa, Fundação Oriente, 2005 (Orientália, n. ${ }^{\circ}$ 10), pp. 186.

716 ANTÓNIO NUNES PEREIRA, op. cit, pp. 186 e 292-293. Observam-se ordens colossais nas igrejas de comunidades vindas diretamente de Itália, ibidem, pp. 326.

717 "Architecture and Mathematics in the Renaissance: proportion systems in two churches in Old Goa of the 16th century", UNIDCOM / IADE, 30.09.2005 - 30.04.2009 (POCI / AUR / 60935 / 2004 and PPCDT / AUR / 60935 / 2004). Este projeto envolveu também o estudo da sé de Goa, mas cujos resultados são menos relevantes para este artigo. Os desenhos aqui apresentados são do autor, em colaboração com os designers Tiago Molarinho Antunes e Sara Eusébio. 
do complexo original da igreja, sacristia, pátio e dependências adjacentes, antes da ampliação dos braços do falso transepto para acomodação da capela funerária de São Francisco Xavier, em 1659.718 A análise dos levantamentos desta igreja da Casa Professa dos jesuítas na antiga capital do Estado da Índia revela a utilização do retângulo 3:4 na configuração do edifício (figs. 11 e 12). Como sabemos, a proporção 3:4, correspondente ao intervalo musical de quarta perfeita, é considerada por Alberti como uma das mais harmónicas e, por isso, recomendadas no projeto arquitetónico. ${ }^{719}$ Contudo, a preferência por esta proporção pode ter igualmente aspetos simbólico-religiosos: se 3 é o número associado à divindade, em particular referindo-se à Santíssima Trindade, 4 é o número associado à terra e à vida terrena. A conjugação de ambos sob a forma de multiplicação origina o número 12 , o número de apóstolos que disseminaram na terra a palavra divina. Esta era a missão que os jesuítas tomaram para si no Oriente, a pregação, não sendo por acaso que a sua figura mias emblemática, Francisco Xavier, foi precisamente chamado o "apóstolo das Índias". ${ }^{720}$

\section{Conclusão}

A análise da receção dos elementos inovadores da prática arquitetónica de Leon Battista Alberti na arquitetura portuguesa "ao modo romano" a partir do século XVI mostra que esta se realizou quase sempre de um modo indireto. Deu-se sobretudo através da influência de edifícios como Il Gesù de Roma que, se por um lado se relacionam com obras de Alberti, por outro mostram evolução em relação à mesmas. Isto explica-se sobretudo pelo desfasamento da receção da obra albertiana em relação à sua produção. Entre

718 PEDRO DIAS, História da Arte Portuguesa no Mundo (1414-1822). O Espaço do Índico, s/local, Círculo de Leitores, 1998, p. 88.

719 LEON BATTISTA ALBERTI, Da arte Edificatória, trad. de A. M. do Espírito Santo, introd., notas e revisão disciplinar de M. J. Krüger, Lisboa, Fundação Calouste Gulbenkian, 2001, pp. 598-599.

720 Os resultados desta investigação encontram-se publicados em ANTÓNIO NUNES PEREIRA, "Renaissance in Goa: Proportional Systems in Two Churches of the Sixteenth Century", em Nexus Network Journal, vol. 13, n 2, 2011, pp. 373-396. 
a morte de Alberti em 1472 e o início da prática do "modo romano" em Portugal decorreu pelo menos o intervalo de duas gerações. Nesse período de tempo a jovem arquitetura do Renacismento sofria sobretudo em Itália grandes alterações, numa renovação criativa constante. Quando o interesse de arquitetos e comitentes em Portugal despertou para a herança clássica renascida, o seu olhar voltou-se para o que de mais recente existia. Nesta altura já inclusivamente se fazia sentir a influência de outras regiões como a França e a Flandres no evoluir da arquitetura renascentista. Em meados do século XVI, os modelos albertianos puros pertenciam a um passado distante e tinham entretanto sido adaptados a novas necessidades e preferências. Contudo, a evolução que a arquitetura do Renascimento teve entre o desaparecimento de Alberti e a sua grande difusão não só pela Europa, mas também pelos territórios recém descobertos e conquistados da Índia às Américas, não nos pode levar a esquecer as suas origens. Traçar alguns destes caminhos desde Alberti até ao edificado "ao romano" é averiguar o processo de génese do Renascimento em Portugal.

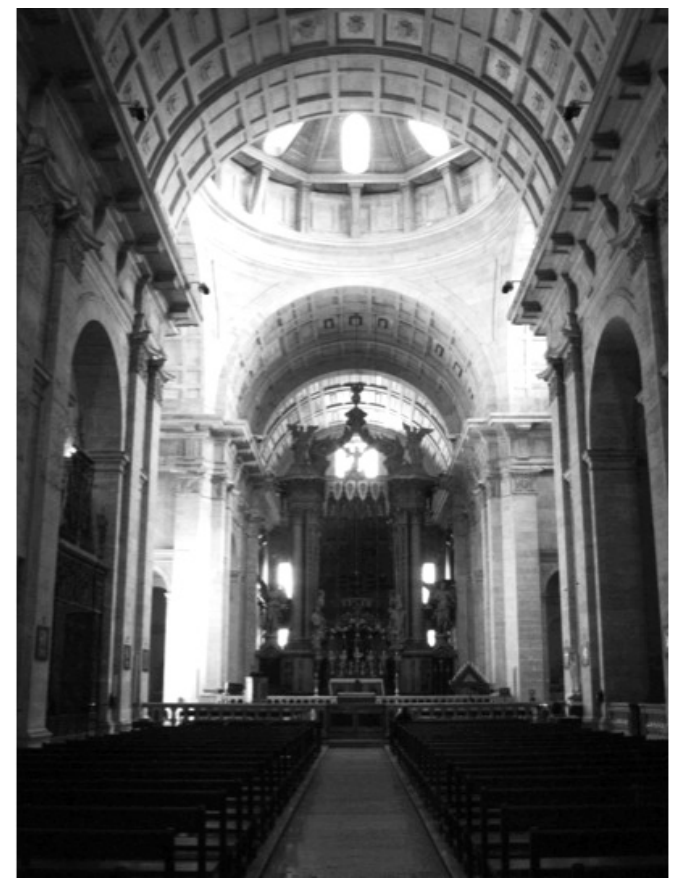

Fig. 1: Interior da igreja São Vicente de Fora, Lisboa. 


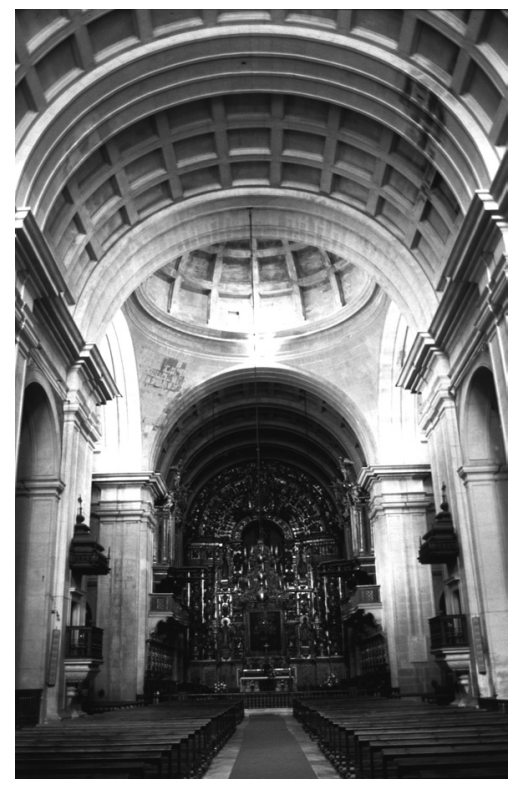

Fig. 2: Interior da igreja das Onze Mil Virgens, Coimbra.

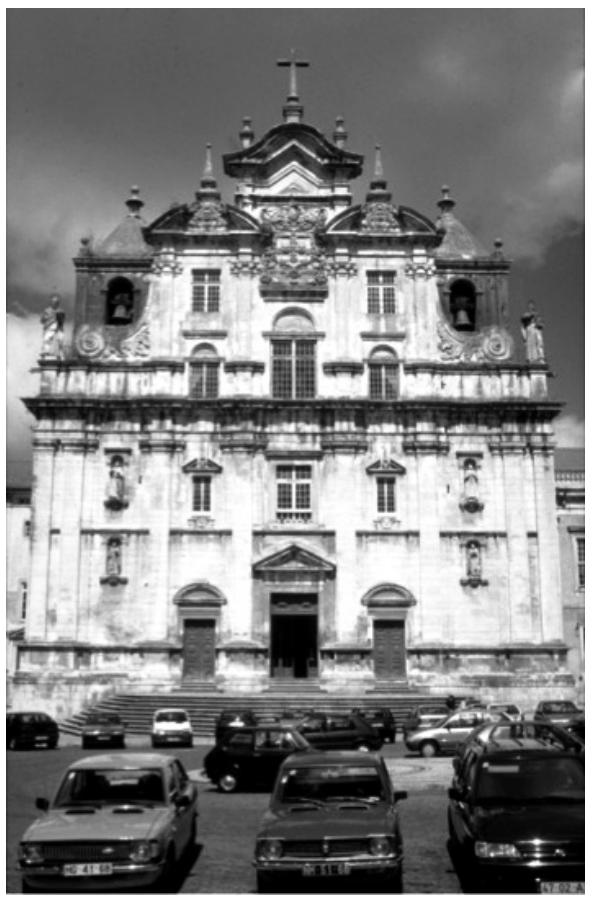

Fig. 3: Fachada da igreja das Onze Mil Virgens, Coimbra. 


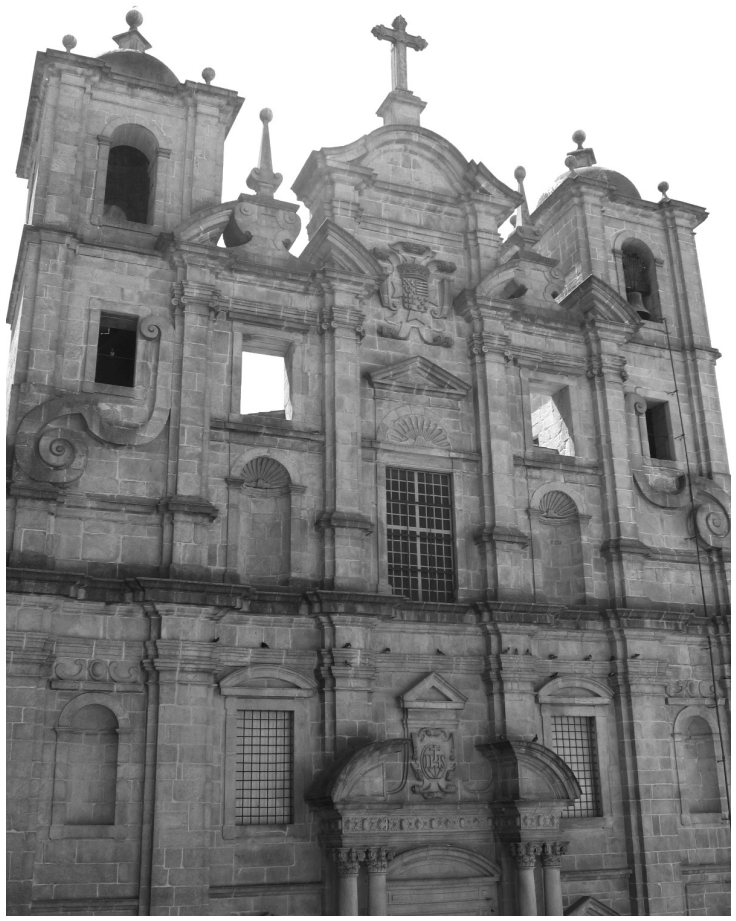

Fig. 4: Fachada da igreja de São Lourenço, Porto.

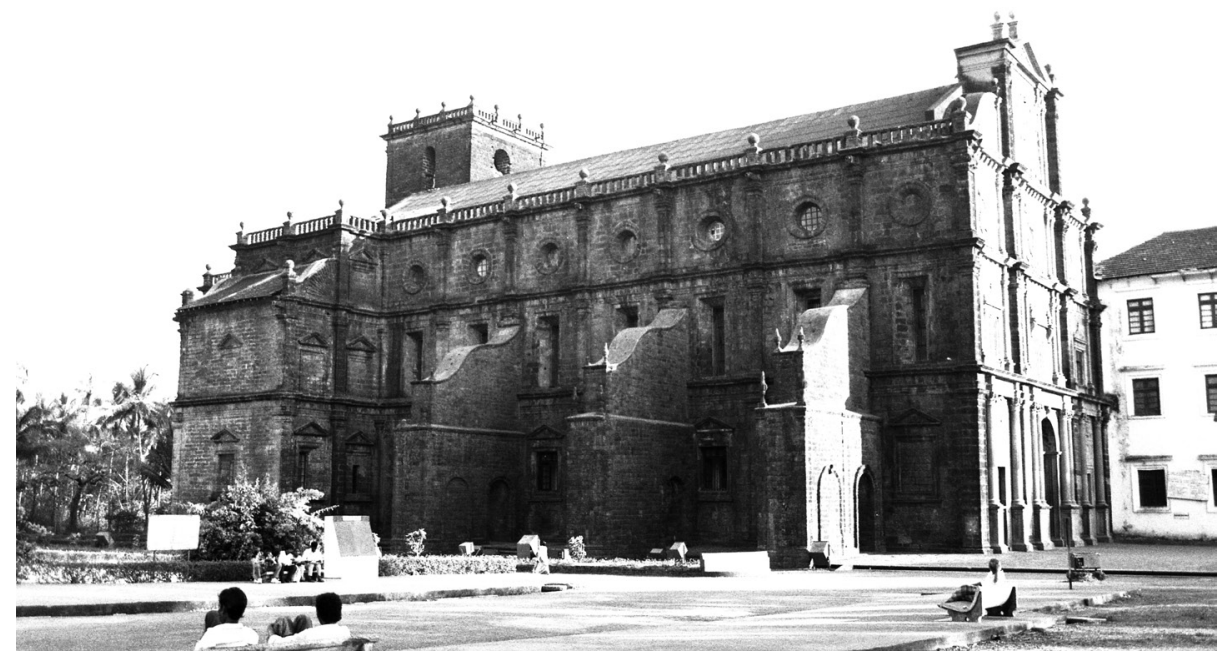

Fig. 5: Exterior da igreja do Bom Jesus, Goa. 


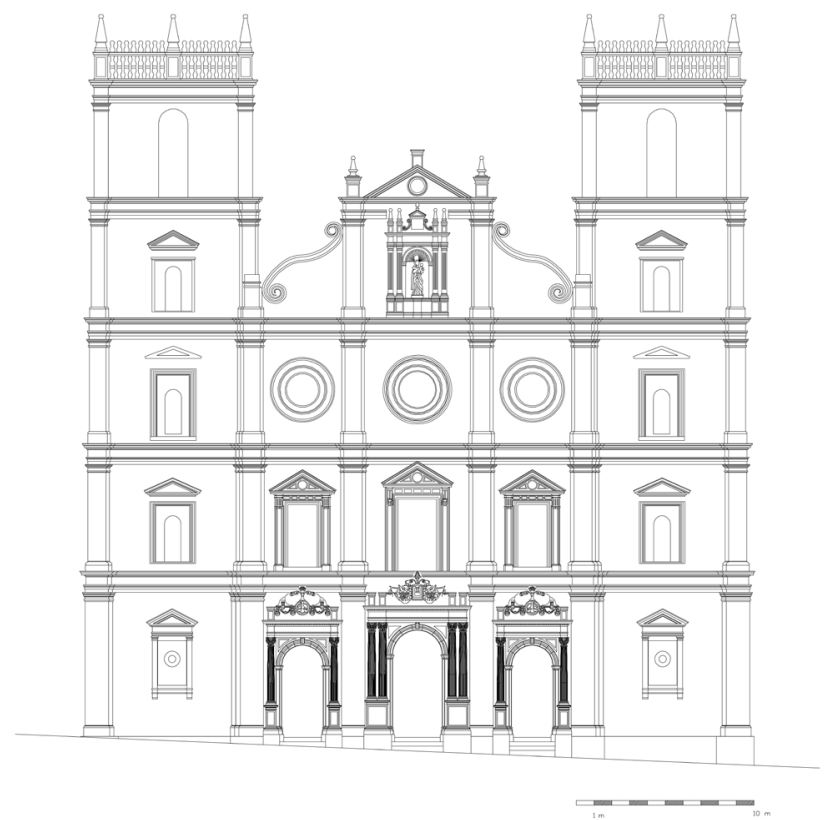

Fig. 6: Reconstituição da fachada da igreja de Nossa Senhora da Graça, Goa (desenho do autor).

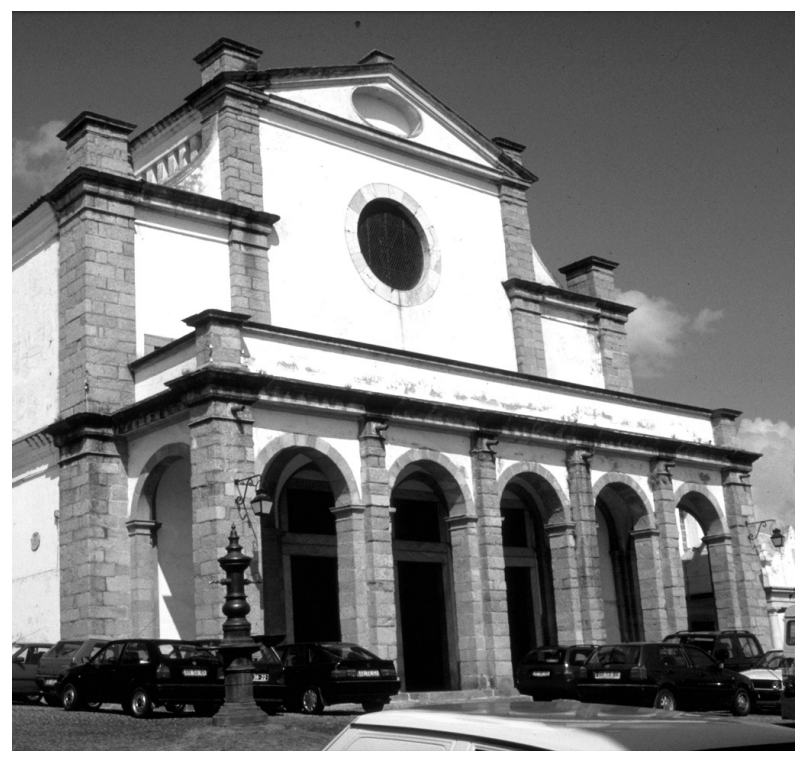

Fig. 7: Igreja do Espírito Santo, Évora. 


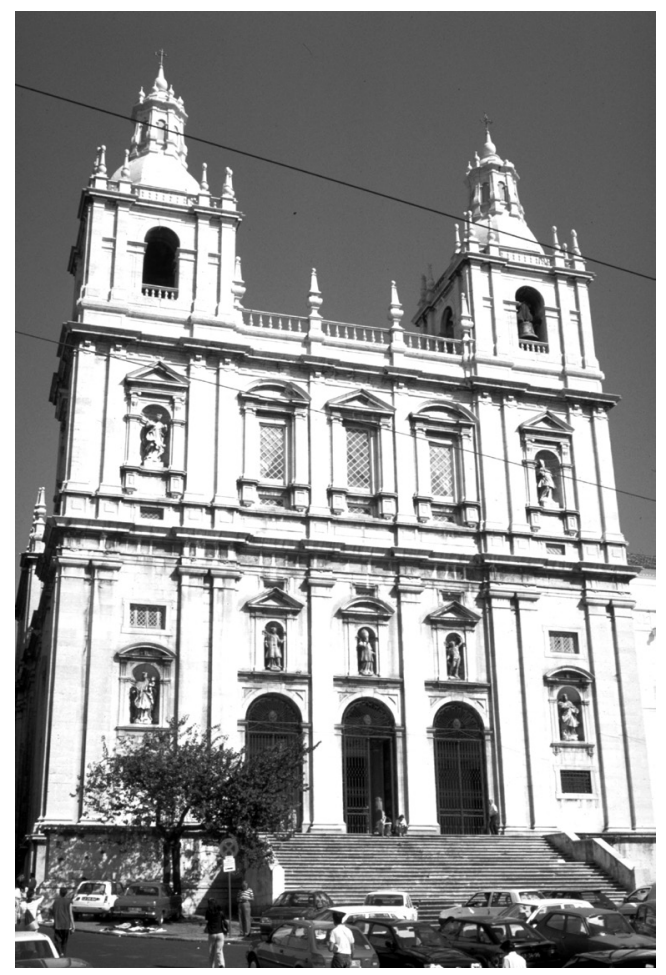

Fig. 8: Igreja de São Vicente de Fora, Lisboa.

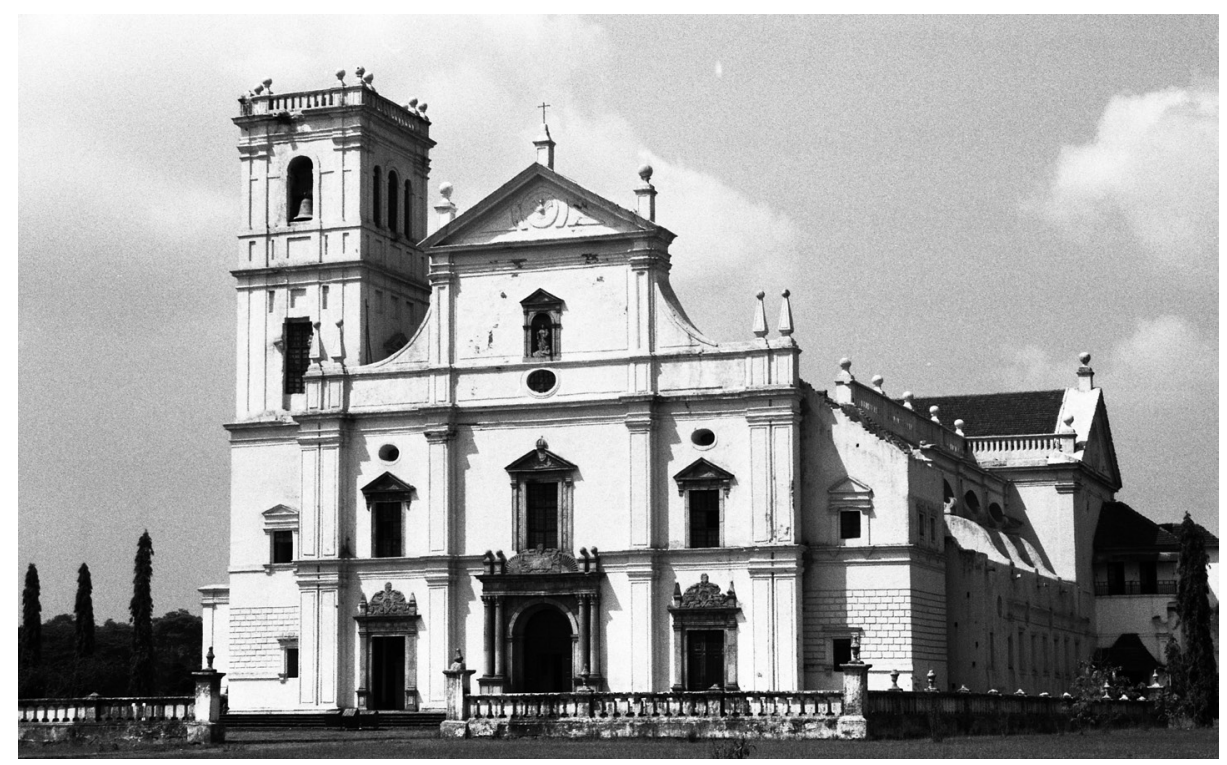

Fig. 9: Sé de Goa. 


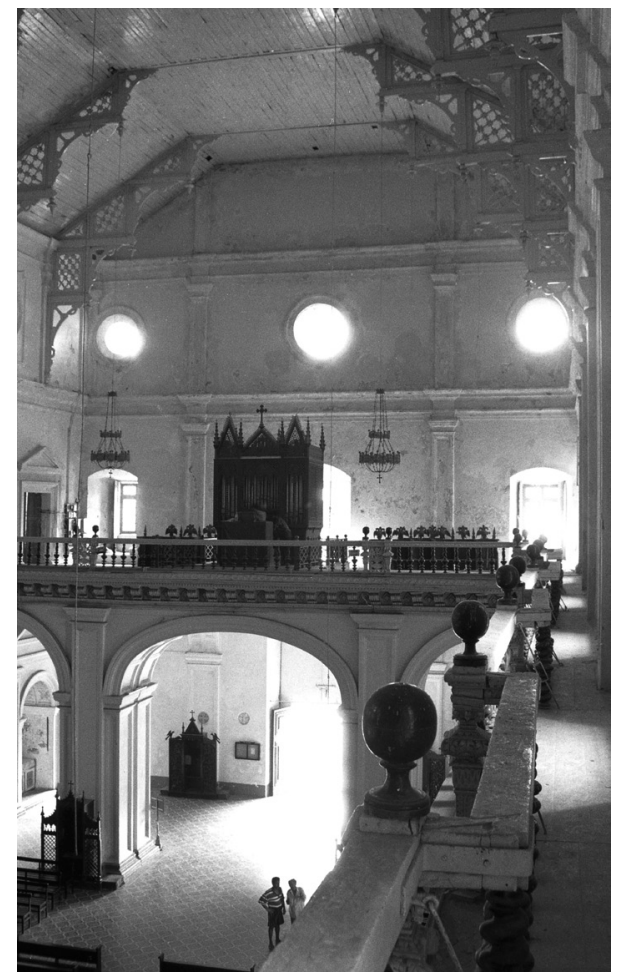

Fig. 10: Interior da igreja do Bom Jesus de Goa.

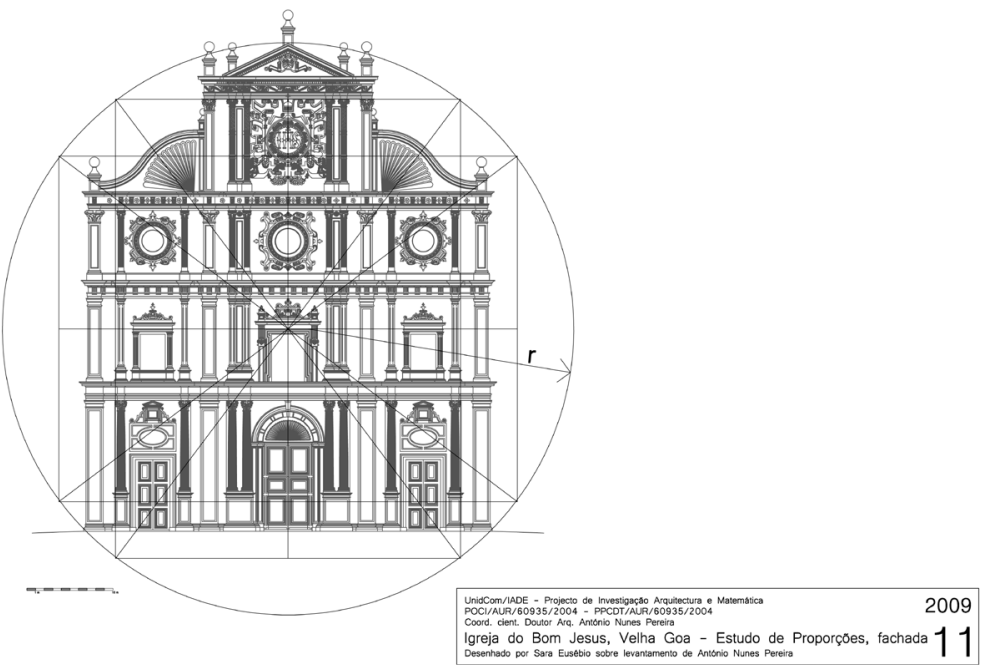

Fig. 11: Fachada da igreja do Bom Jesus de Goa (desenho do autor). 


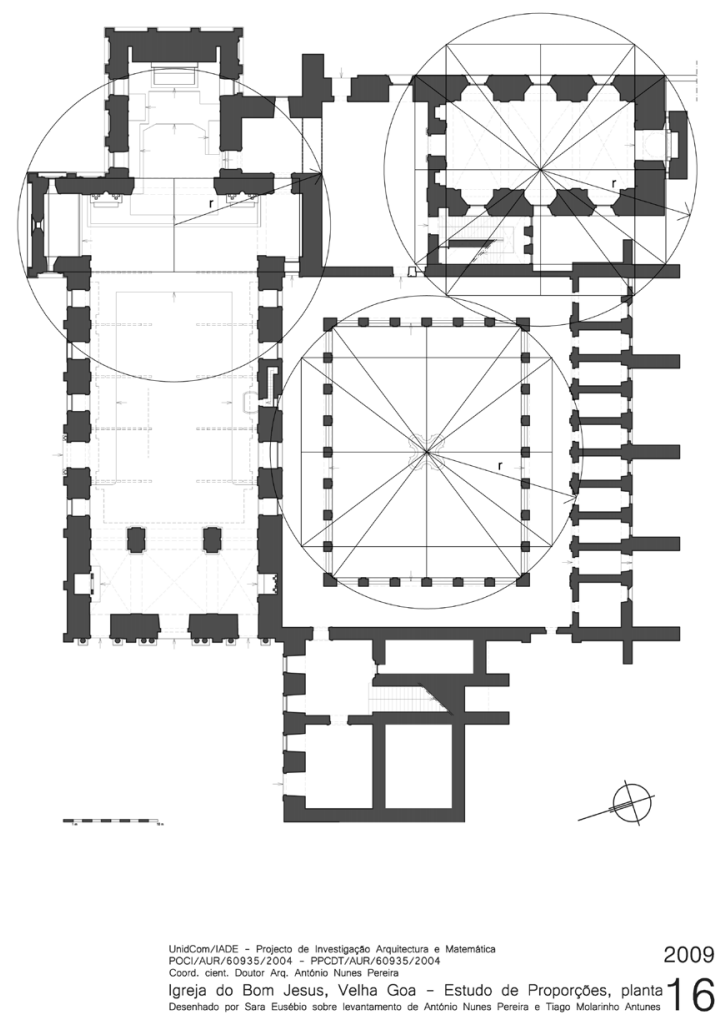

Fig. 12: Planta da igreja e claustro anexo do Bom Jesus de Goa (desenho do autor). 